\title{
In Vitro and In Vivo Experimental Hepatotoxic Models in Liver Research: Applications to the Assessment of Potential Hepatoprotective Drugs
}

\author{
H. FARGHALI ${ }^{1}$, M. KGALALELO KEMELO ${ }^{1}$, L. WOJNAROVÁ ${ }^{1}$, \\ N. KUTINOVÁ CANOVÁ ${ }^{1}$
}

${ }^{1}$ Institute of Pharmacology, First Faculty of Medicine, Charles University, Prague, Czech Republic

Received July 25, 2016

Accepted September 12, 2016

\begin{abstract}
Summary
This mini-review highlights our and others' experience about in vitro and in vivo models that are being used to follow up events of liver injuries under various hepatotoxic agents and potential hepatoprotective drugs. Due to limitations of the outcomes in each model, we focus primarily on two models. First, a developed perfusion method for isolated immobilized hepatocytes that improves the process of oxygenation and helps in end-product removal is of considerable value in improving cell maintenance. This cellular model is presented as a short-term research-scale laboratory bioreactor with various physiological, biochemical, molecular, toxicological and pharmacological applications. Second, the in vivo model of D-galactosamine and lipopolysaccharide (D-GaIN/LPS) combination-induced liver damage is described with some details. Recently, we have revealed that resveratrol and other natural polyphenols attenuate D-GalN/LPS-induced hepatitis. Moreover, we reported that D-GaIN/LPS down-regulates sirtuin 1 in rat liver. Therefore, we discuss here the role of sirtuin 1 modulation in hepatoprotection. A successful development of pharmacotherapy for liver diseases depends on the suitability of in vitro and in vivo hepatic injury systems. Several models are available to screen the hepatotoxic or hepatoprotective activity of any substance. It is important to combine different methods for confirmation of the findings.
\end{abstract}

\section{Key words}

Liver diseases - Hepatotoxicity models • D-Galactosamine/Lipopolysaccharide • Resveratrol • SIRT1 activators

\section{Corresponding author}

N. Kutinová Canová, Institute of Pharmacology, First Faculty of Medicine, Charles University in Prague, Albertov 4, 12800 Prague 2, Czech Republic. Fax: +420224968 106. E-mail: ncano@lf1.cuni.cz

\section{Introduction}

The global numerous causes and incidence for liver disease, including viral hepatitis, HIV, obesity with the consequent non-alcoholic fatty liver disease (NAFLD), excessive chronic alcohol consumption, immune and cholestatic disorders, inherited metabolic disorders, numerous medications, hemochromatosis, schistosomiasis, and fungi infections among others, necessitate a thorough investigation using appropriate models for liver disease. Moreover, liver diseases such as fibrosis are a major worldwide health problem, with high prevalence in developing countries where hundreds of millions are afflicted (Sanchez-Valle et al. 2012). In fact, with the global obesity epidemic, NAFLD, and the ensuing nonalcoholic steatohepatitis (NASH), fibrosis, cirrhosis and hepatocellular carcinoma have become a worldwide health concern of all ages and ethnicities (Alonso et al. 2010, Nobili et al. 2011, Torres et al. 2012).

A successful development of therapy for the liver depends on the availability of in vitro and in vivo test model systems for hepatic injury. Several models are available to screen the antihepatotoxic activity of any substance. Since there are limitations of the outcomes in 
each model, it is important to combine different methods for confirmation of the findings (Muriel 2007, Farghali et al. 2015).

This mini-review highlights our and others' experience about liver injury models that are being used to follow up events of liver injuries under hepatotoxic agents following biochemical, histological, and molecular events in hepatocytes under various conditions. Examples of applications of various in vitro and in vivo models in using synthetic chemicals or purified or semi-purified chemicals of herbal origins (i.e. chemically defined molecules) with reported experimental and/or clinical hepatoprotective activity are presented. The findings are likely to help further investigate hepatotoxic and hepatoprotective agents at both the experimental and the clinical levels. Based on these advances, a number of inflammatory targets have been identified with the potential for therapeutic intervention in various liver injuries by using certain compounds, presenting new opportunities and challenges for translational research.

Moreover, in this article, we consider briefly literature related to some studied active plant constituents of chemically defined molecules with potential hepatoprotective activity and the models most commonly used for their validation. We believe that these findings will certainly increase the likelihood of using hepatoprotective agents of well-defined molecules with less adverse effects, and will help design new molecules by using computational and synthetic chemistry. Naturally, this requires examination of the molecular aspects of studied compound mode of actions. This may seem more intricate since both the impairment of the liver is multifactorial (viral or protozoal infections, chronic use of excessive alcohol, drugs, xenobiotics etc.) and the chemoprotective agents are different in their chemical structures. Therefore, there is an urgent need to find out a range of efficient drugs that may be classified as hepatoprotective agents through the application of various in vitro and in vivo injury models.

\section{In vitro experimental hepatotoxic models in liver research}

There are several in vitro models like hepatocyte cultures and perifused hepatocytes that examine pathophysiological injuries due to various treatments (e.g. hepatotoxins, hypoxia or anoxia, anoxia/reoxygenation) (Farghali et al. 1991, Gasbarrini et al. 1992, Farghali et al. 2000, Farghali 2008, Cerný et al. 2009).
Freshly isolated cells in suspension, primary cell cultures, and clonal cell lines are examples of well-established cellular models from various laboratories that have contributed significantly to the understanding of many aspects of mammalian cell physiology and molecular biology. Nevertheless, such cells may be metabolically less active than the corresponding cells in vivo, due to inefficient oxygenation and build-up of waste products. Therefore, herein we focus on a developed perifusion method for isolated cells that improves the process of oxygenation and helps in end-product removal and is likely to be of considerable value in improving cell maintenance (Gillies et al. 1986, Donoghue et al. 1992, Gillies et al. 1993, MacDonald et al. 1998).

\section{Short-term research-scale laboratory bio- reactor}

Hepatocytes, isolated by the collagenase method, are now being very extensively used in biological and biomedical studies (Berry et al. 1991). The availability of an effective hepatocyte perifusion system would be of considerable value. More than 30 years ago, there were a few preliminary trials of hepatocyte perifusion followed by several reports on various methods of cell immobilization for perifusion studies, using either animal or plant cells. A description of hepatocyte immobilization for perifusion purposes in a small or research-scale laboratory bioreactor was described in detail previously (Gillies et al. 1986, Gillies et al. 1993, Farghali et al. 1994, Farghali and Hynie 1997, Farghali 2008) and is briefly outlined here.

\section{Advantages and shortcomings of cellular immobilization}

\section{Advantages:}

Perifusion of immobilized cells facilitates the oxygenation process, and assists end-product removal, thus contributing to cell survival.

Cells can be used for continuous monitoring of various metabolic and pathophysiological processes.

Uncontaminated cellular products can be recovered readily for further processing.

The flexibility of bioreactor design allows new approaches to the solution of special problems in biomedical research.

The availability of a bioreactor reduces the need for whole organ studies. 
The limited use of immobilized hepatocytes to date may reflect the following shortcomings:

The lack of agreed optimal procedures for cell immobilization.

Mechanical problems in achieving efficient and uniform perifusion.

The relative instability of the immobilized hepatocyte systems so far developed.

\section{Methods of cell immobilization}

Currently, cell immobilization may be summarized under 5 processes, namely, adsorption, covalent binding, encapsulation, entrapment and crosslinking (Gillies et al. 1993, Bickerstaff 1997). Since there are large number of possible permutations between methods of immobilization and support material, it is easier to simplify the methods of cell immobilization into four major categories (Foxall et al. 1984, Donoghue et al. 1992, MacDonald et al. 1998):

The thread technique: cells are mixed with a liquid gel (agarose gel, calcium alginate or matrigel) that is allowed to solidify, entrapping the cells in threads.

Microcarrier beads: cells are cultured on the surface of solid or porous charged plastic beads.

Hollow fiber systems: cells are grown using commercially available hollow fiber systems which are suitable for cellular proliferation.

Perifusion of cells in culture dishes.

\section{Isolation of rat hepatocytes}

Small animals like rats or mice may be used for the isolation of hepatocytes by the standard two-phase perfusion method where collagenase is included in the second phase (Berry et al. 1991). The hepatocytes are counted and examined for integrity. Hepatocyte suspensions in which Trypan blue is excluded by more than $90 \%$ of the cells should be used.

\section{Hepatocyte immobilization in agarose gel threads and assessing hepatocyte function- nality and integrity in the agarose gel matrix}

Although the hollow fiber method is perhaps more physiological than other methods, and is used in bioartificial liver support systems, the thread method is outlined here because of to its simplicity and the ease with which it can be performed after short practice. The details of the methods of immobilization in agarose gel threads and perifusion with the appropriate medium were outlined in reference (Farghali et al. 1994, Farghali and Hynie 1997, Farghali 2008).

\section{An outline of some applications of immobilized cells}

Among the applications of bioreactor is the study of nuclear magnetic resonance spectroscopy (NMR) of cells which allows for noninvasive and on-line analyses of many biochemical cell events which is known as real-time measurements. ${ }^{31} \mathrm{P}-\mathrm{NMR}$ can be employed to gain information about the intracellular $\mathrm{pH}$ and the energetic status of cells and some phosphorus-containing xenobiotics can be used for drug metabolism studies (Farghali et al. 1991, Kaplan et al. 1992). ${ }^{13} \mathrm{C}$ - and ${ }^{1} \mathrm{H}-\mathrm{NMR}$ spectroscopy are also powerful tools for cellular metabolic studies (Mancuso et al. 1994). Generally, further applications of immobilized cells include:

In vitro biochemical, physiological, pharmacokinetic, pharmacodynamic and toxicity studies.

Immobilized and perifused cells as bioartificial organs.

Monoclonal antibody production and study of recombinant proteins. The feasibility of producing high amounts specific monoclonal antibodies was assessed and it was found that cells in a hollow fiber bioreactor can provide significant amounts of monoclonal antibody (Goodall 1998).

Viral vectors. The use of mammalian cell bioreactor technology has enabled scientists to successfully implement bioreactor technology for the engineering of viral vectors (Shankar et al. 1997).

More recently, we have used this model in the study of the resveratrol effects as compared to silymarin pretreatments on tert-butylhydroperoxide $(\mathrm{tBH})$ induced apoptotic/necrotic markers in hepatocytes (Cerný et al. 2009). Hepatocyte in cultures (48 h) and in perifused immobilized agarose threads $(5 \mathrm{~h})$ were used as cellular systems. Resveratrol and silymarin reduced tBH-induced hepatocyte toxic effects in short term experiments as measured by a significant reduction in alanin-aminotransferase (ALT) and nitric oxide (NO) increase produced by $\mathrm{tBH}$. Both inducible nitric oxide synthase (NOS-2) and hemoxygenase-1 (HO-1) gene expression were increased by $\mathrm{tBH}$ and reduced by both resveratrol and silymarin pretreatments. Morphologically, there were ameliorations in both apoptotic and necrotic markers under resveratrol treatment (Cerný et al. 2009). 
This cellular model is also sensitive for detection of minimal enzyme metabolizing activity. It was reported that rat liver microsomes display, practically, no O-dealkylating activity toward 7-ethoxycoumarin and on the other hand it was demonstrated an accumulation of 7-ethoxycoumarin de-ethylated product umbelliferone in the perfusate of induced and noninduced hepatocytes. The use of the present model demonstrated that even a minimum deethylase activity in rat liver could be detected in a hepatocyte bioreactor (Kameníková et al. 1994, Farghali and Hynie 1997, Farghali 2008).

\section{In vivo experimental hepatotoxic models in liver research}

A number of in vivo models are depicted in Figure 1 that demonstrates common experimental setups in small animals. In the present article we discuss the model of D-galactosamine and lipopolysaccharide (D-GalN/LPS) combination with some detail since it is the most frequently used model for our in vivo studies. Other models shown in Figure 1 are used widely as well (Muriel 2007).

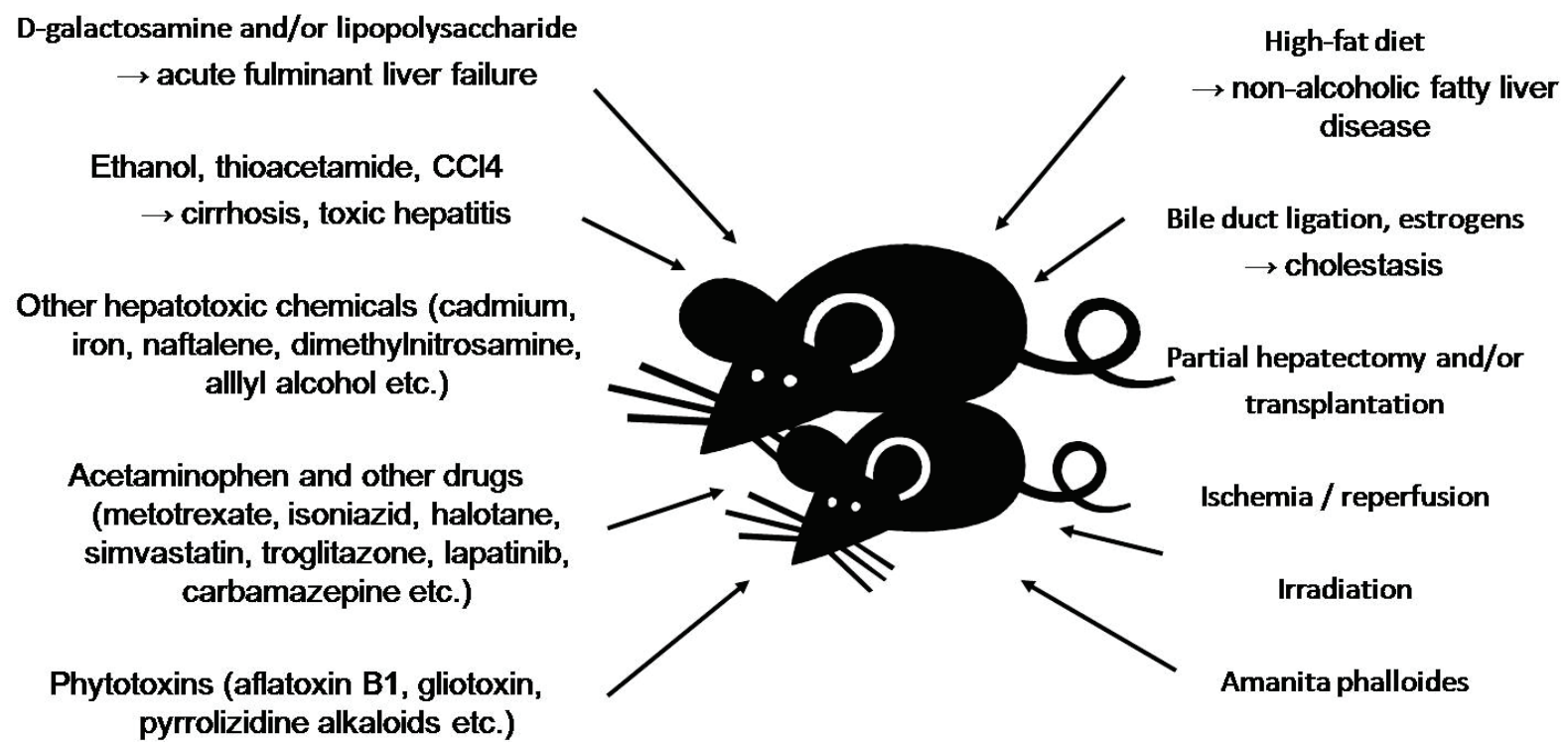

Fig. 1. Common in vivo models of liver damage.

\section{D-galactosamine/lipopolysaccharide-induced fulminant liver failure and acetaminophen- induced liver injury}

The combination of both D-GalN and LPS produces significant hepatic injury due to combined prooxidant mechanisms and consequently oxidative stress. It was known earlier that $\mathrm{D}-\mathrm{GalN}$ results in vivo in the depletion of uridine phosphate pool due to the formation of UDP-D-GalN derivatives which leads to the inhibition of mRNA and protein synthesis (Keppler et al. 1974). Later on, it was recognized that reactive oxygen species, perhaps, contribute mainly to D-GalN-induced hepatotoxicity due to roles played by macrophages and Kupffer cells in vivo (Stachlewitz et al. 1999). Moreover, LPS induces cytokine(s) as TNF-alpha results in oxidative stress (Neihorster et al. 1992).

At present, it is clear that the combination of D-GalN and LPS causes definite oxidative stress in vivo and leads to fulminant liver failure.

Nowadays, D-GalN/LPS-induced hepatitis is a well established model of LPS-induced liver injury or septic shock (Freudenberg et al. 1986, Morikawa et al. 1999, Xiong et al. 1999, Van Dien et al. 2001, Motobu et al. 2006, Thorlacius et al. 2006, Liu et al. 2008, Farghali et al. 2009). Various dose combinations of LPS and D-GalN were used to produce sublethal liver failure which is relevant to clinical situations in viral, drug or alcohol-induced, immune-induced or ischemia reperfusion hepatitis. In our studies, we used increasing doses of LPS from $0.5 \mu \mathrm{g} / \mathrm{kg}$ to $50 \mu \mathrm{g} / \mathrm{kg}$ combined with decreasing doses of D-GalN from $800 \mathrm{mg} / \mathrm{kg}$ to $200 \mathrm{mg} / \mathrm{kg}$. The combination of $10 \mu \mathrm{g} / \mathrm{kg}$ LPS with $400 \mathrm{mg} / \mathrm{kg}$ D-GalN produced a nonlethal hepatitis as proved histologically and biochemically evidenced by increases in ALT, AST, alpha-GST, NO, and the mRNA levels of the studied genes (Farghali et al. 2009). Therefore, D-GalN/LPS combinations with different 
amounts of D-GalN/LPS appear very well reproducible model for in vivo experimental hepatitis studies (Lekić et al. 2013, Kemelo et al. 2014, Kemelo et al. 2016). Moreover, a single dose of acetaminophen (APAP, $1 \mathrm{~g} / \mathrm{kg}$ ) was applied to rat to produce mild degree of hepatotoxicity (Wojnarova et al. 2015). This model of mild hepatic impairment more resembles the human APAP-induced liver injury.

\section{Resveratrol and related compounds as antioxidants in D-GalN/LPS-induced hepatoxicity: role of sirtuin 1 modulation in hepatoprotection}

As described in the earlier section of this review (in vitro models), investigated naturally occurring cytoprotective agents such as resveratrol (trans-3,4',5-trihydroxystilbene) and other related compounds, probably with similar molecular mechanisms of action, have the potentials of applications in medical fields. Several physiological aspects have been ascribed to resveratrol and similar compounds including silymarin, curcumin, quercetin, and glycyrrhizin (Farghali et al. 2013, Farghali et al. 2015).

Indeed, we have shown that rat pretreatment with resveratrol before D-GalN/LPS application not only modified most of the oxidative parameters as thiobarbituric acid reacting substances and conjugated dienes or the antioxidants as catalase, but more importantly, NOS-2 and HO-1 gene-expression were significantly modulated (Farghali et al. 2009). Thus, it was revealed that this naturally occurring cytoprotective compound exhibited a degree of hepatoprotection in a liver disease model of reversible fulminant hepatic failure.

Resveratrol, among others, has been recently described as a silent information regulator T1 (SIRT1 or sirtuin 1) activator that increases AMP-activated protein kinase (AMPK) phosphorylation and reduces the oxidative damage biomarkers during aging in laboratory settings. The reports on resveratrol and other SIRT1 activators from various sources are encouraging. The pharmacological strategies for modulation of sirtuins by small molecules through allosteric mechanisms should gain a greater momentum including human research. Resveratrol and resveratrol-like molecules seem to fulfill the requirement of a new horizon in drug research since these molecules cover a growing research means as antioxidants with allosteric mechanism in epigenetic drug targets. However, one should keep in mind the challenges of extrapolation of basic research into clinical results. Overall, the issue of sirtuins in biology and disease provides an insight on therapeutic potentials of sirtuinbased therapeutics and demonstrates the high complexity of drug-targeting these modalities for human applications.

The studies of Kemelo (Kemelo et al. 2014, Kemelo et al. 2016) reported that D-GalN/LPS-induced hepatotoxicity downregulates SIRT1 in rat liver and discussed the role of sirtuin 1 modulation in hepatoprotection. The role of sirtuin 1 in this model has not been documented before. However, there have been vast numbers of studies about the cytoprotective effects of resveratrol, a SIRT1 activator, in the liver and other tissues. This study was directed to elucidate the roles of SIRT1 protein expression or catalytic activity in D-GalN/LPS model of hepatotoxicity. Some groups of animals were pretreated with resveratrol, quercetin or a selective SIRT1 activator, SRT1720, and/or with a specific SIRT1 inhibitor, EX-527. The effects of these treatments were evaluated by biochemical and Western blot methods. D-GalN/LPS treatment was able to induce a dramatic decrease of SIRT1 protein levels in liver tissue. Resveratrol, quercetin and SRT1720 pretreatments attenuated D-GalN/LPS-induced hepatotoxicity and simultaneously upregulated SIRT1 expression (Kemelo et al. 2014, Kemelo et al. 2016). Conversely, EX-527 blocked the hepatoprotective effects of resveratrol (Kemelo et al. 2014). Moreover, resveratrol and another synthetic selective activator of sirtuin 1, CAY10591, increased SIRT1 activity and attenuated APAP-induced rat hepatotoxicity both in vivo and in vitro (Wojnarová et al. 2015). Collectively, these results suggest that downregulation of SIRT1 expression and/or activity is involved in the cytotoxic effects of D-GalN/LPS and APAP and that SIRT1 activity contributes to the cytoprotective effects of resveratrol in the liver.

\section{Recent developments of in vitro and in vivo hepatotoxic models in liver research}

An in vitro platform for evaluating liver toxicity was described by Bale (Bale et al. 2014). The authors addressed a predictive human in vitro model and introduced a paradigm of microfluidic culture systems with the goal to mimic the liver with physiologically relevant dimensions, cellular structure, perifusion, and mass transport by taking advantage of micro and nanofabrication technologies. High-content analysis/ 


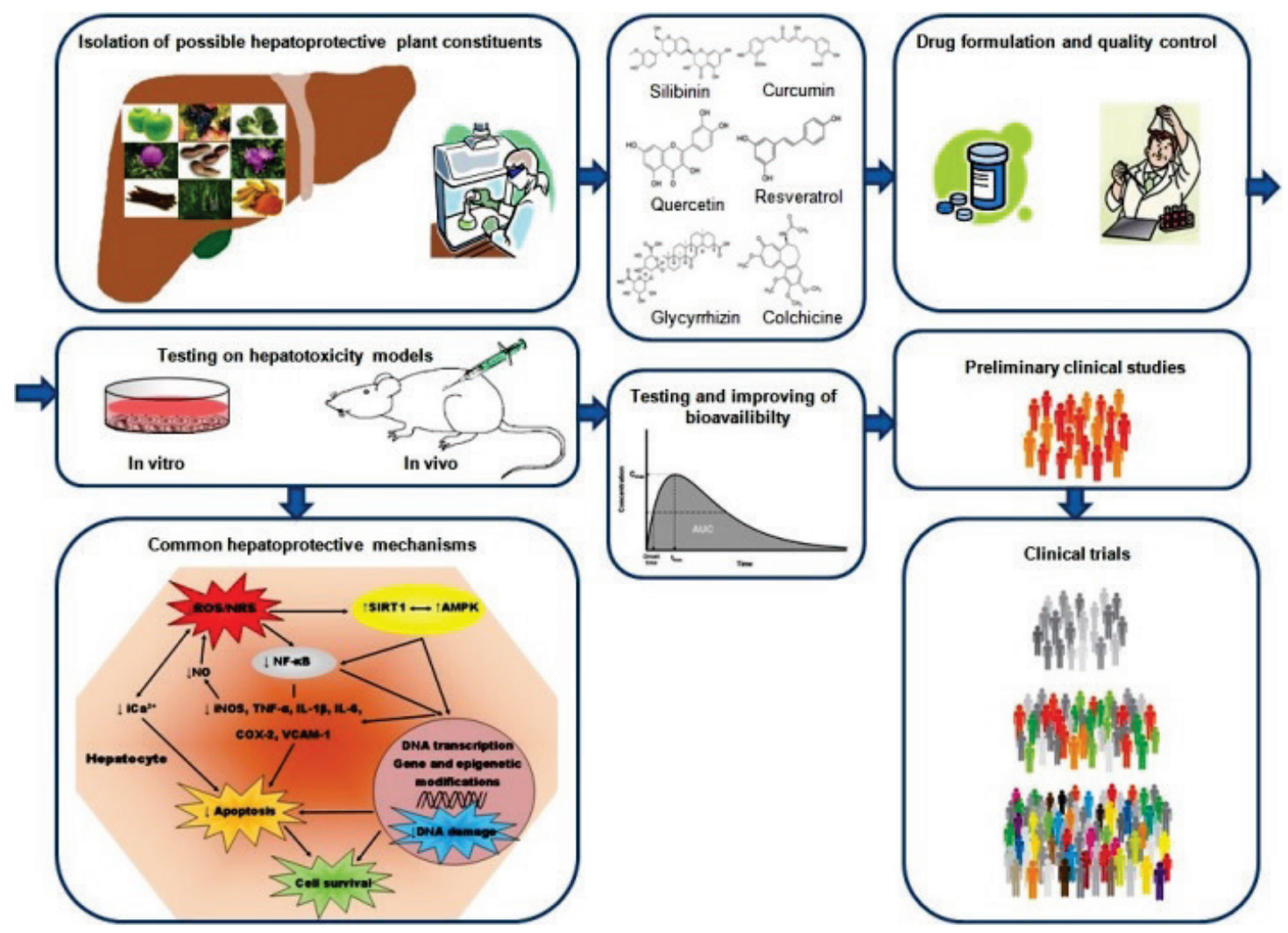

Fig. 2. Steps in development of potential hepatoprotective therapy for liver diseases.

screening for predictive hepatotoxicity and the evaluation of database-derived pathway development for enabling biomarker discovery for hepatotoxicity were also recently described (Hebels et al. 2014, Persson et al. 2014).

Although, higher vertebrate organisms (for example rodents and pigs) are physiologically similar to humans, and have been traditionally used for studying in vivo drug-induced liver injury, smaller, lower order vertebrates, such as the zebrafish (Danio rerio), can be also used for this approach. The zebrafish can accurately model human physiology and offer, beside its limitations, some significant advantages (rapid development of liver, large numbers of transparent embryo, low overall cost etc.), compared to rodents and other larger animals. However and as reported, before the model can be applied on wider scale, more validation is needed to confirm the translatability of the model to humans (Vliegenthart et al. 2014).

\section{Discussion and concluding remarks}

The application of in vitro and in vivo experimental hepatotoxic models in liver research is essential to understand and assess mechanisms of liver toxicity and to study potential hepatoprotective drugs.
Isolated hepatocytes in suspension, primary cell cultures, and clonal cell lines are examples of well-established cellular models from various laboratories that have contributed significantly to the understanding of many aspects of liver physiology and molecular biology. Nevertheless, such cells may be metabolically less active than the corresponding cells in vivo, due to inefficient oxygenation and build-up of waste products. Therefore, we focus on a developed perifusion method for isolated cells that improves the process of oxygenation and helps in end-product removal that is likely to be of considerable value in improving cell maintenance in the so-called short-term research scale small laboratory bioreactor.

A number of in vivo models are described and we discussed the model of D-GalN/LPS combination with some detail since it is the most widely used model for our in vivo studies. We are using this model for more than 16 years. We gained more insights on the molecular aspect of this combination and the use of natural and synthetic cytoprotective agents as modulators of toxicity. Beside alteration in conventional and molecular toxicity parameters, we described very recently the effect of this combination on SIRT1 reduction in the liver and the amelioration produced by some natural and synthetically (e.g. SRT1720 and CAY10591) produced SIRT1 
allosteric modulators.

A successful development of therapy for the liver depends on the suitability of in vitro and in vivo test model systems for hepatic injury. Several models are available to screen the antihepatotoxic activity of any substance. Moreover, we briefly described recent developments of in vitro and in vivo hepatotoxic models in liver research which may reveal an excellent contribution to the study of hepatotoxicity and hepatoprotection in the near future.

Since there are limitations of the outcomes in each model, it is important to combine different methods for confirmation of the findings as we have demonstrated in this mini-review. In addition, the future is to carry out controlled prospective double blind multicenter studies with newly identified potential lead hepatoprotective drugs of natural or related newly synthesized origin with proven beneficial preclinical in vitro and in vivo effects (Fig. 2).

\section{Conflict of Interest}

There is no conflict of interest.

\section{Acknowledgements}

This study was supported by the research program PRVOUK-P25/LF1/2 and grant GAUK-916314.

\section{References}

ALONSO FT, GARMENDIA ML, DE AGUIRRE M, SEARLE J: Mortality trend from liver cirrhosis in Chile from 1990 to 2007. Rev Med Chil 138: 1253-1258, 2010.

BALE SS, VERNETTI L, SENUTOVITCH N, JINDAL R, HEGDE M, GOUGH A, MCCARTY WJ, BAKAN A, BHUSHAN A, SHUN TY, GOLBERG I, DEBIASIO R, USTA OB, TAYLOR DL, YARMUSH ML: In vitro platforms for evaluating liver toxicity. Exp Biol Med (Maywood) 239: 1180-1191, 2014.

BERRY MN, EDWARDS AM, BARRIT JG: Isolated hepatocytes preparation, properties and applications. In: Laboratory Techniques in Biochemistry and Molecular Biology 21. BURDON RH, VAN KNIPPENBERG PH (eds), Elsevier, Amsterdam, 1991, pp 1-460.

BICKERSTAFF GF: Immobilization of enzymes and cells, some practical consideration. In: Methods in Biotechnology. BICKERSTAFF GF (ed.), Humana Press, Totowa, New Jersey, 1997, pp 1-11.

CERNÝ D, KUTINOVÁ CANOVÁ N, MARTÍNEK J, HORÍNEK A, KMONÍCKOVÁ E, ZÍDEK Z, FARGHALI H: Effects of resveratrol pretreatment on tert-butylhydroperoxide induced hepatocyte toxicity in immobilized perifused hepatocytes: involvement of inducible nitric oxide synthase and hemoxygenase-1. Nitric Oxide 20: $1-8,2009$.

DONOGHUE C, BRIDEAU M, NEWCOMER P, PANGRLE B, DIBIASIO D, WALSH E, MOORE S: Use of magnetic resonance imaging to analyze the performance of hollow-fiber bioreactors. Ann N Y Acad Sci 665 : 285-300, 1992.

FARGHALI H, SAKR M, GASBARRINI A, WILLIAMS DS, DOWD SR, HO C, VAN THIEL DH: A biochemical and 31P-NMR investigation of the effect of FK 506 and cyclosporine pretreatment on immobilized hepatocytes perifused with ethanol. Transplant Proc 23: 2805-2808, 1991.

FARGHALI H, KAMENÍKOVÁ L, HYNIE S: Preparation of functionally active immobilized and perfused mammalian cells: an example of hepatocyte bioreactor. Physiol Res 43: 121-125, 1994.

FARGHALI H, HYNIE S: Hepatocytes immobilization in agarose and functional integrity testing. In: Methods in Biotechnology. BICKERSTAFF GF (ed.), Humana Press, Totowa, New Jersey, 1997, pp 175-184.

FARGHALI H, KMONÍCKOVÁ E, LOTKOVÁ H, MARTÍNEK J: Evaluation of calcium channel blockers as potential hepatoprotective agents in oxidative stress injury of perfused hepatocytes. Physiol Res 49: 261-268, 2000.

FARGHALI H: Perifused immobilized hepatocytes for metabolic studies. In: Hepatocyte Review. BERRY MN, EDWARDS AM (eds), Kluwer Academic Publishers, Dordrecht, 2008, pp 181-193.

FARGHALI H, CERNÝ D, KAMENÍKOVÁ L, MARTÍNEK J, HORÍNEK A, KMONÍCKOVÁ E, ZÍDEK Z: Resveratrol attenuates lipopolysaccharide-induced hepatitis in D-Galactosamine sensitized rats: role of nitric oxide synthase 2 and heme oxygenase-1. Nitric Oxide 21: 216-225, 2009. 
FARGHALI H, KUTINOVÁ CANOVÁ N, LEKIĆ N: Resveratrol and related compounds as antioxidants with an allosteric mechanism of action in epigenetic drug targets in combined LPS and D-GalN toxicity. Physiol Res 62: 1-13, 2013.

FARGHALI H, KUTINOVÁ CANOVÁ N, ZAKHARI S: Hepatoprotective properties of extensively studied medicinal plant active constituents: possible common mechanisms. Pharmaceut Biol 53: 781-791, 2015.

FOXALL DL, COHEN JS, MITCHELL JB: Continuous perifusion of mammalian cells embedded in agarose gel threads. Exp Cell Res 154: 521-529, 1984.

FREUDENBERG MA, KEPPLER D, GALANOS C: Requirement for lipopolysaccharide responsive macrophages in galactosamine-induced sensitization to endotoxin. Infect Immun 51: 891-895, 1986.

GASBARRINI A, BORLE AB, CARACENI P, FARGHALI H, FAGIUOLI S, AZZARONE A, ZETTI G, STARZL TE, VAN THIEL DH: Hepatocytes anoxic injury is prevented by high concentration of fructose. Transplant Proc 24: 2810-2811, 1992.

GILLIES RJ, CHRESAND TJ, DRURY PD, DALE BE: Design and application of bioreactors for analyses of mammalian cells by NMR. Rev Magn Reson Med 1: 155-179, 1986.

GILLIES RJ, GALONS JP, MCGOVERN KA, SCHERER PG, LIEN YH, JOB C, RATCLIFF R, CHAPA F, CERDAN S, DALE BE: Design and application of NMR-compatible bioreactor circuits for extended perifusion of high-density mammalian cell cultures. NMR Biomed 8: 95-104, 1993.

GOODALL M: A simple hollow-fiber bioreactor for the "in-house" production of monoclonal antibodies. In: Immunochemical Protocols, (2nd edn). POUND JD (ed.), Humana Press, Totowa, New Jersey, 1998, pp 39-56.

HEBELS DG, JETTEN MJA, AERTS HJW, HERWIG R, THEUNISSEN DHJ, GAJ S, VAN DELFT JH, KLEINJANS JC: Evaluation of database-derived pathway development for enabling biomarker discovery for hepatotoxicity. Biomark Med 8: 185-200, 2014.

KAMENÍKOVÁ L, FARGHALI H, MISEKOVÁ D, LINCOVÁ D, HYNIE S: Application of the hepatocytes bioreactor to xenobiotic biotransformation. Physiol Res 43: 127-130, 1994.

KAPLAN O, VAN ZIJL PCM, COHEN JS: NMR studies of metabolism of cells and perfused organs. In: NMR Basic Principles and Progress. SEELING J, RUDIN M (eds), Springer-Verlag, Berlin, 1992, pp 3-52.

KEMELO MK, WOJNAROVÁ L, KUTINOVÁ CANOVÁ N, FARGHALI H: D-galactosamine/lipopolysaccharideinduced hepatotoxicity downregulates sirtuin 1 in rat liver: Role of sirtuin 1 modulation in hepatoprotection. Physiol Res 63: 615-623, 2014.

KEMELO MK, KUTINOVÁ CANOVÁ N, HORÍNEK A, FARGHALI H: Comparative effects of quercetin and SRT1720 against D-Galactosamine/lipopolysaccharide-induced hepatotoxicity in rats: Biochemical and molecular biological investigations. Eur Rev Med Pharmacol Sci 20: 363-371, 2016.

KEPPLER DO, PAUSCH J, DECKER K: Selective uridine triphosphate deficiency induced by D-galactosamine in liver and reversed by pyrimidine nucleotide precursors. Effect on ribonucleic acid synthesis. J Biol Chem 249: 211-216, 1974.

LEKIĆ N, FARGHALI H, KUTINOVÁ CANOVÁ N, HORÍNEK A: The involvement of heme oxygenase 1 but not nitric oxide synthase 2 in a hepatoprotective action of quercetin in lipopolysaccharide-induced hepatotoxicity of D-galactosamine sensitized rats. Fitoterapia 87: 20-26, 2013.

LIU LM, ZHANG JX, LUO J, GUO HX, DENG H, CHEN JY, SUN SL: A role of cell apoptosis in lipopolysaccharide (LPS)-induced nonlethal liver injury in D-galactosamine (D-GalN)-sensitized rats. Dig Dis Sci 53: 1316-1324, 2008.

MACDONALD JM, GRILLO M, SCHMIDLIN O, TAJIRI DT, JAMES TL: NMR spectroscopy and MRI investigation of a potential bioartificial liver. NMR Biomed 11: 55-66, 1998.

MANCUSO A, SHARFSTEIN ST, TUCKER SN, CLARK DS, BLANCH HW: Examination of primary metabolic pathways in a murine hybridoma with carbon-13 nuclear magnetic resonance spectroscopy. Biotech Bioeng 44 : 563-585, 1994.

MORIKAWA A, KATO Y, SUGIYAMA T, KOIDE N, CHAKRAVORTTY D, YOSHIDA T, YOKOCHI T: Role of nitric oxide in lipopolysaccharide-induced hepatic injury in D-galactosamine-sensitized mice as an experimental endotoxic shock model. Infect Immun 67: 1018-1024, 1999. 
MOTOBU M, AMER S, KOYAMA Y, HIKOSAKA K, SAMESHIMA T, YAMADA M, NAKAMURA K, KOGE K, KANG CB, HAYASIDANI H, HIROTA Y: Protective effects of sugar cane extract on endotoxic shock in mice. Phytother Res 20: 359-363, 2006.

MURIEL P: Some experimental models in liver damage. In: Hepatotoxicity: From Genomics to in vitro and in vivo Models. (1th edn). SAHU SC (ed.), John Wiley \& Sons Inc, Chichester, 2007, pp 119-137.

NEIHORSTER M, INOUE M, WENDEL A: A link between extracellular reactive oxygen and endotoxin-induced release of tumor-necrosis-factor-alpha in vivo. Biochem Pharmacol 43: 1151-1154, 1992.

NOBILI V, CARTER-KENT C, FELDSTEIN AE: The role of lifestyle changes in the management of chronic liver disease. BMC Med 9: 70, 2011.

PERSSON M, LOYE AF, JACQUET M, MOW NS, THOUGAARD AV, MOW T, HORNBERG JJ: High-content analysis/screening for predictive toxicology: application to hepatotoxicity and genotoxicity. Basic Clin Pharmacol Toxicol 115: 18-23, 2014.

SANCHEZ-VALLE V, CHAVEZ-TAPIA NC, URIBE M, MENDEZ-SANCHEZ N: Role of oxidative stress and molecular changes in liver fibrosis: A review. Curr Med Chem 19: 4850-4860, 2012.

SHANKAR R, WHITELY CB, PAN D, BURGER S, MCCULLOUGH J, STRONCEK D: Retroviral transduction of peripheral blood leukocytes in a hollow-fiber bioreactor. Transfusion 37: 685-690, 1997.

STACHLEWITZ RF, SEABRA V, BRADFORD B, BRADHAM CA, RUSYN I, GERMOLEC D, THURMAN RG: Glycine and uridine prevent D-galactosamine hepatotoxicity in the rat: role of Kupffer cells. Hepatology 29: 737-745, 1999.

THORLACIUS K, SLOTTA JE, LASCHKE MW, WANG YS, MENGER MD, JEPPSSON B, THORLACIUS H. Protective effect of fasudil, a Rho-kinase inhibitor, on chemokine expression, leukocyte recruitment, and hepatocellular apoptosis in septic liver injury. J Leukoc Biol 79: 923-931, 2006.

TORRES DM, WILLIAMS CD, HARRISON SA: Features, diagnosis, and treatment of nonalcoholic fatty liver disease. Clin Gastroenterol Hepatol 10: 837-858, 2012.

VAN DIEN M, TAKAHASHI K, MU MM, KOIDE N, SUGIYAMA T, MORI I, YOSHIDA T, YOKOCHI T: Protective effect of Wogonin on endotoxin-induced lethal shock in D-galactosamine-sensitized mice. Microbiol Immunol 45: 751-756, 2001.

VLIEGENTHART ADB, TUCKER CS, DEL POZO J, DEAR JW: Zebrafish as model organisms for studying druginduced liver injury. Br J Clin Pharmacol 78: 1217-1227, 2014.

WOJNAROVÁ L, KUTINOVÁ CANOVÁ N, FARGHALI H, KUCERA T: Sirtuin 1 modulation in rat model of acetaminophen-induced hepatotoxicity. Physiol Res 64 (Suppl. 4): S477-S487, 2015.

XIONG QB, HASE K, TEZUKA Y, NAMBA T, KADOTA S: Acteoside inhibits apoptosis in D-galactosamine and lipopolysaccharide-induced liver injury. Life Sci 65: 421-430, 1999. 